Disclosure of Interests: None declared

DOI: 10.1136/annrheumdis-2021-eular.2620

\section{AB0794 CONTRIBUTION OF LABIAL SALIVARY GLAND BIOPSY: EXPERIENCE OF THE DEPARTMENT OF RHEUMATOLOGY OF THE UNIVERSITY HOSPITAL OF IBN ROCHD (ABOUT 57 CASES)}

Z. El Ouali ${ }^{1}$, A. Elkebir ${ }^{2}$, K. Nassar ${ }^{1}$, M. Karkouri ${ }^{2}$, S. Janani ${ }^{1} .{ }^{1}$ University Hospital of Ibn Rochd, Department of Rheumatology, Casablanca, Morocco; ${ }^{2}$ University Hospital of Ibn Rochd, Department of Anatomical Pathology, Casablanca, Morocco

Background: Labial salivary gland biopsy (LSGB) is a histological examination indicated for the diagnostic workup of systemic diseases such as Sjogren's syndrome, amyloidosis, or sarcoidosis.

Objectives: To study the contribution of LSGB to the diagnosis of Sjogren's syndrome, amyloidosis, and sarcoidosis.

Methods: We conducted a retrospective study of LSGB histopathological reports and clinical data of patient medical records collected in the Department of Rheumatology of the University Hospital of Ibn Rochd, Casablanca, between January 2019 and June 2020. Histology assessed Chisholm and Masson's sialadenitis score, looked for amyloidosis, and sarcoidotic granulomas.

Results: A total of 57 LSGBs were performed, of which 2 were excluded from our study because of lack of clinical data. The sex-ratio $\mathrm{M} / \mathrm{F}$ was 0.1 , and the median age was $53(22-85)$. The indications were subjective eyes and mouth dryness in $40 \%$ of cases, the search for sarcoidosis and amyloidosis in $23.6 \%$ of cases, the assessment of a dryness syndrome in the context of chronic inflammatory rheumatism in $18.2 \%$ of cases, isolated dryness of the mouth in $14.5 \%$ of cases, and the search for amyloidosis in the context of a known primary Sjögren syndrome in $3.6 \%$ of cases. The stages of Chisholm and Masson for sialadenitis found were: stage I at $56.6 \%$, stage II at $24.5 \%$, stage III at $11.3 \%$, and stage IV at $7.5 \%$. Among the LSGBs performed for dryness syndrome, stages III and IV were found in $18.2 \%$ of cases among subjective eyes and mouth dryness, in $12.5 \%$ of cases among isolated mouth dryness, and in $20 \%$ of cases among chronic inflammatory rheumatisms. Three cases of AA amyloidosis (5.5\%) were diagnosed. No sarcoidosis granulomas were found. Conclusion: LSGB is a simple and frequent investigation. The Chisholm stage most often found in our series was stage I, followed by stages II, III, and IV respectively. This is consistent with the results of the study of Baeteman et al (1). In addition, amyloidosis was only found in our series in $5.5 \%$ of cases, also matching with the results of Baeteman et al. (4.2\%). Their study showed that LSGB has a great diagnostic interest in these two pathologies, with a sensitivity of $52-75 \%$ and a specificity of $90-100 \%$ for Sjogren's syndrome, and a sensitivity of $48-80 \%$ and a specificity of 93-100\% for amyloidosis (2). LSGB remains a simple investigation test, contributing to the diagnosis of Sjogren's syndrome, amyloidosis, and sarcoidosis.

REFERENCES:

[1] Baeteman C, Guyot L, Bouvenot J, Chossegros C, Cheynet F, Loudot C, et al. Faut-il encore effectuer des biopsies des glandes salivaires accessoires ? Revue de Stomatologie et de Chirurgie Maxillo-faciale. 2008 Jun;109(3):143-7.

[2] Scardina GA, Spanó G, Carini F, Spicola M, Valenza V, Messina P, et al. Diagnostic evaluation of serial sections of labial salivary gland biopsies in Sjögren's syndrome. Med Oral Patol Oral Cir Bucal. 1 déc 2007;12(8):E565-568.

Disclosure of Interests: None declared

DOI: 10.1136/annrheumdis-2021-eular.2755

\section{AB0795 \\ DYNAMIC CHANGES IN QUANTITATIVE INDICES OF BODY COMPOSITION BY DUAL-ENERGY X-RAY ABSORPTIOMETRY IN PATIENTS WITH EARLY RHEUMATOID ARTHRITIS ON DIFFERENT THERAPEUTIC REGIMENS}

Y. Gorbunova ${ }^{1}$, T. Popkova ${ }^{1}$, T. Panafidina ${ }^{1}$, N. Demin ${ }^{2}$, E. Nasonov ${ }^{3}$, A. Lila ${ }^{3}$. ${ }^{1}$ VA Nasonova Research Institute of Rheumatology, Department of Systemic Rheumatic Diseases, Moskva, Russian Federation; ${ }^{2}$ VA Nasonova Research Institute of Rheumatology, Department of Osteoporosis, Moskva, Russian Federation; ${ }^{3}$ VA Nasonova Research Institute of Rheumatology, Scientific Department, Moskva, Russian Federation

Background: A redistribution of body fat (abdominal obesity) is quite common in RA patients. Such parameters as body mass index (BMI) and waist circumference do not distinguish or quantify fat and lean (muscle) mass. For that purpose, dual-energy X-ray absorptiometry (DXA) is usually used.

Objectives: to compare quantitative body composition in patients with early RA at baseline and after 24 weeks of therapy with different regimens.

Methods: The study included 37pts (31 women /6 men) with early RA (ACR/ EULAR criteria, 2010), $57[46.5,62,0]$ years old, naïve to treatment with glucocorticoids and disease-modifying anti-rheumatics (DMARDs). Pts were seropositive for IgM RF (76\%) and anti-CCP (92\%), with highly active RA (DAS28 5,5 [5,1; 6,0]; SDAI 32,4 [22,4; 42], CDAI 29,0 [19,7; 39,5]) scores, and median disease duration of $6.0[5,5 ; 15.5]$ months. Methotrexate (MTX) 10 [10-15] mg/week subcutaneously was initiated in all included patients as first line therapy for 12 weeks. By this time point therapy was reviewed in 19 patients $(51 \%)$ due to MTX inefficacy and adalimumab (ADA) at $40 \mathrm{mg}$ once every 2 weeks was added on top of MTX. DXA scan (HOLOGIC, USA) was used to measure body composition at baseline and after 6 mths of treatment with the protocol assessing total body, body fat and lean muscle mass.

Results: Based on therapeutic regimens at week 24 all study subjects were divided into 2 groups: Group I ( $n=18)$ receiving MTX monotherapy, Group II $(n=19)$ - the combination of MTX and ADA (Table 1). Group I patients had lower body weight, lean and fat mass vs patients from Group II $(62 \mathrm{~kg}$ vs. $73.7 \mathrm{~kg}$ $40.6 \mathrm{~kg}$ vs. $49.7 \mathrm{~kg} ; 21.0 \mathrm{~kg}$ vs. $25.8 \mathrm{~kg}$, respectively ( $<<0.05$ in all cases) at baseline. 24 weeks of combination therapy eventuated in body weight gain $(73.7 \mathrm{~kg}$ vs. $75.8 \mathrm{~kg})$, accumulation of fat $(25.8 \mathrm{~kg}$ vs. $28.1 \mathrm{~kg})$ and unchanged lean tissue mass. In contrast, patients on MTX monotherapy managed to increase their lean mass $(40.6 \mathrm{~kg}$ vs. $41.6 \mathrm{~kg})$ without gaining in total fat mass.

Table 1.

\begin{tabular}{|c|c|c|c|c|c|c|}
\hline \multirow[t]{2}{*}{ Indices } & \multicolumn{3}{|c|}{$\begin{array}{l}\text { I group }(n=18) \text {, } \\
\text { monotherapy MT }\end{array}$} & \multicolumn{3}{|c|}{$\begin{array}{l}\text { II group ( } n=19) \text {, } \\
\text { combination therapy (MTX, ADA) }\end{array}$} \\
\hline & baseline & 24 weeks & $\Delta, \%$ & baseline & 24 weeks & $\Delta, \%$ \\
\hline $\begin{array}{l}\text { Body fat mass, } \\
\quad \mathrm{kg}\end{array}$ & $21,0[17,2 ; 26,2]^{* *}$ & $23,4[17,5 ; 29,7]$ & +11 & $25,8[18,4 ; 35,0]$ & $28,1[21,4 ; 37,9]^{*}$ & +9 \\
\hline Lean mass, $\mathrm{kg}$ & $40,6[37,3 ; 44,7]^{* *}$ & $\begin{array}{c}41,6[38,2 ; 46,4]^{* * / /} \\
*\end{array}$ & $+2,5$ & $49,7[39,0 ; 56,1]$ & $49,9[41,0 ; 57,6]$ & 0,4 \\
\hline
\end{tabular}

${ }^{*} \mathrm{p}<0,05$ reliability of differences in parameters before treatment and after $6 \mathrm{mth}$ (Wilcoxon); ${ }^{* *} p<0.05$ differences in baseline values in groups I and II (Mann-Whitney test); ${ }^{* \star \star} p<0.05$ dif ference in the indices between the groups by the $6 \mathrm{mth}$ of therapy; $\Delta, \%$ difference in indices between the groups by the $6 \mathrm{mth}$ of therapy.

Conclusion: In general, RA patients on treatment tend to gain weight by week 24 Patients who failed on MTX monotherapy by week 24 and were switched to combination therapy had higher fat mass at baseline. Mediations used for RA treatment produce multidirectional effects on quantitative parameters of body composition: MTX monotherapy triggers some increase of lean mass, while combination of MTX and bDMARD results in weight gain and increase of total and fat mass. These data need to be confirmed in large-scale studies with longer follow-up period.

Disclosure of Interests: None declared

DOI: 10.1136/annrheumdis-2021-eular.3115

\section{AB0796}

THE EVALUATION OF LUNG DIAGNOSTIC PROCEDURE AT THE ONSET OF INFLAMMATORY RHEUMATIC DISEASES WITH INTERSTITIAL LUNG DISEASE

T. Hoffmann ${ }^{1}$, P. Oelzner ${ }^{1}$, F. Marcus ${ }^{2}$, M. Förster ${ }^{2}$, J. Böttcher ${ }^{3}$, G. Wolf ${ }^{1}$, A. Pfeil'. ${ }^{1}$ Jena University Hospital - Friedrich Schiller University Jena, Department of Internal Medicine III, Jena, Germany; ${ }^{2}$ Jena University Hospital - Friedrich Schiller University Jena, Department of Internal Medicine I, Jena, Germany; ${ }^{3}$ Jena University Hospital - Friedrich Schiller University Jena, Institute of Diagnostic and Interventional Radiology, Jena, Germany

Background: Interstitial lung disease (ILD) in inflammatory rheumatic diseases (IRD) is associated with increased mortality. Moreover, the lung is one of the most effected organs on IRD. Consequently, screening methods were required to the detect ILD in IRD.

Objectives: The objective of the following study is to evaluate the diagnostic value of lung function test, chest $\mathrm{x}$-ray and HR-CT of the lung in the detection of ILD at the onset of IRD.

Methods: The study is designed as a case-control study and includes 126 patients with a newly diagnosed IRD. It was matched by gender, age and the performance of lung function test and chest $\mathrm{x}$-ray. The sensitivity and specificity were verified by crosstabs and receiver operating characteristic (ROC) curve analysis. The study cohort was divided in two groups (ILD group: $n=63$ and control group: $n=63$ ). If possible, all patients received a lung function test and optional a chest $x$-ray. Patients with pathological findings in the screening tests (chest x-ray or reduced diffusing capacity for carbon monoxide (DLCO) $<80 \%$ ) maintained a high-resolution computer tomography (HR-CT) of the lung. Additionally, an immunological bronchioalveolar lavage was performed in the ILD group as gold standard for the detection of ILD. Results: The DLCO (<80\%) revealed a sensitivity of $83.6 \%$ and specificity of $45.8 \%$ for the detection of ILD. Other examined parameter of lung function tes showed no sufficient sensitivity as screening test (FVC = Forced Vital Capacity, FEV1 = Forced Expiratory Volume in 1 second, TLC = Total Lung Capacity, TLCO $=$ Transfer factor of the Lung for carbon monoxide). Also, a combination of different parameter did not increase the sensitivity. The sensitivity and specificity of chest $x$-ray for the verification of ILD was $64.2 \%$ versus $73.6 \%$. The combination of DLCO (<80\%) and chest x-ray showed a sensitivity with $95.2 \%$ and specificity with $38.7 \%$. The highest sensitivity $(95.2 \%)$ and specificity $(77.4 \%)$ was observed for the combination of DLCO (<80\%) and HR-CT of the lung. 